\title{
Language and IT Service Outsourcing
}

\author{
Li Liu \\ Xiamen University Tan Kah Kee College, Zhangzhou 363105, China \\ liuli101@xujc.com
}

\begin{abstract}
Keywords: Language, IT service outsourcing, Gournot competition model.
\end{abstract}
\begin{abstract}
The main goal of this paper is to discover how language affects a country's capability to export computer and information services as well other ICT-enabled services. It provides theoretical and empirical analysis on the role played by language in export of IT-enabled services. The estimation results are consistent with theoretical hypothesis that productivity, the Internet and language contribute to a country's ability to export computer and information services. Countries where English is the official language or widely spoken have a significant advantage over their competitors in exports of computer and information services.
\end{abstract}

\section{Introduction and Literature Review}

This paper will be an attempt to contribute to this interesting area in international economics, focusing on the determinants of a country's export volume of Computer and Information Services and ICT-Enabled Services (ITES) as a whole, with the latter quite often deemed interchangeable with the term "service offshoring" or "international service outsourcing". In particular, I am interested to find out how significant and in what channels language is affecting ITES export, a question that has been ignored by empirical research to date.

Theoretical studies on outsourcing mainly focus on demand side: how firms make a two-dimensional decision regarding internalization versus outsourcing, and home production versus offshoring. Little has been said about what makes the exporting firms and countries competitive service suppliers. Instead of developing new models, studies normally refer to more traditional trade theories to find out the determinants of supply side of service outsourcing. James Markusen(2005) developed a series of models out of existing trade theories, simulating the trade patterns of white-collar service offshoring, but only with ambiguous results.

Very few empirical studies on the determinants of a country's competitiveness in ICT-enabled services exist. The most frequently used tools are gravity models with bilateral service trade flows as dependent variable, such as Feund and Weinhold (2004) which emphasizes the importance of the Internet in boosting trade in services. When it comes to trade in ICT-enabled services, bilateral data is still too scarce and unreliable to form any dataset for econometric estimation. This research is anteceded by two empirical studies using cross-sectional country-level data(Jing 2007, Xue and Song 2008). Jing(2007) is only concerned about absolute human capital level and finds out that it is positively related to a country's export of ICT-enabled services, while Xue and Song(2008) conclude that labor cost, skill level, ICT infrastructure and per capita GDP are all significant contributing factors. Both suffer from the problem of small sample size, the former with only 25 and the latter with 41 observations.

This paper is different from the above-mentioned studies in two aspects. First, it will use panel data with sample size large than 200; second, among all the factors affecting a country's export of ITES, the author will try to focus on the role played by language. A relevant empirical study is Melitz(2008) exploring how language affects bilateral merchandise trade volume. Another finding of Melitz(2004) is that English does not possess any special advantage over the other tongues in promoting trade in goods, while European languages as a whole do contribute to trade growth. Besides, it is worth mentioning that almost all empirical research using gravity models, such as Helliwell (1999), show that linguistic ties lead to larger flows of commodity trade. 


\section{The Model}

The computer and information service sector is characterized by a fixed cost of entry, hence, I extend Freund and Weinhold (2004) model with segmented markets and imperfect competition to demonstrate how fixed cost and marginal cost vary with "language distance". I consider N countries, each with a fixed number of firms, ni, specializing in providing computer and information service. Competition in this market is Cournot, and welfare gains are a result of the increase in competition that trade introduces. Demand for the imperfectly competitive computer and information service in country $\mathrm{j}$ is $\mathrm{Pj}=\mathrm{Kj}-\mathrm{Qj}$, where $\mathrm{Pj}$ is price and $\mathrm{Kj}$ is a constant. Markets are assumed to be segmented, that is, it is prohibitively costly to cross-haul output. Each firm in country i produces with a constant marginal cost, $\mathrm{Ci}$. Ci can be further decomposed into $\mathrm{Ci} 1$ and $\mathrm{Ci} 2$, reflecting country i's productivity in computer and information service and internet development respectively. In addition, there is a communication cost, tij that varies with the languages spoken by the service providers and clients. The "language distance" is denoted by dij, it determines tij as follows $t_{i j}=w d_{i j}$, where w is a constant. It remains a challenge to determine the exactly values of dij between different country pairs.

We further assume that each foreign firm incurs a market-specific fixed cost in order to participate in a given market. Specifically, we assume that the fixed cost of a firm from country i entering market $\mathrm{j}$ is drawn from a uniform distribution between 0 and Fijmax: The intuition for the variation in costs within a country is that some firms are likely to have different information about or connection with a particular market.I first solve for the firms optimal exports, given that the firm exports to a certain market, and then I check under what condition exporting will occur in equilibrium. The firm's problem is to maximize net profits

$$
\max q_{i j}=q_{i j}\left(K_{j}-q_{j}^{\bullet}-q_{i j}-c-w d_{i j}\right)-F_{i j}
$$

where qij is the export quantity of a firm from $\mathrm{i}$ in market $\mathrm{j}$, and $\mathrm{qj} *$ is the output for sale by other firms in $\mathrm{j}$. The solution to this problem yields the equilibrium quantity that the firm from $\mathrm{i}$ exports to $\mathrm{j}$ as a function of output from all other firms.

$$
q_{i j}=\frac{\left(K_{j}-c_{i 1}-c_{i 2}-n_{j} w d_{i j}+w \sum_{k \neq i} d_{k j}\right)}{n_{j}+1}
$$

where $\mathrm{nj}$ is the total number of firms competing in market j. Substituting Equation (2) into Equation (1) gives the gross profits

$$
\pi_{i j}=q_{i j}^{2}
$$

With a fixed cost of entering foreign market, exporting is worthwhile only if profits exceed the fixed cost. Let Fij* be defined as the cutoff level of fixed cost in each country such that a firm is willing to export. Entry will occur up to the point where net profits are zero $\pi_{i j}-\bar{F}_{i j}=0$.

Therefore, it can be shown that the share of firms from country $i$ that export to country $j$ is equal to the realized gross profits of each firm that entered market $\mathrm{j}$ relative to the maximum fixed cost, $\pi_{i j} / F_{i j}^{\max }$.

Total exports from $\mathrm{i}$ to $\mathrm{j}, \mathrm{Xij}$, are dependent on the share of firms that export, the quantity that each firm exports, and the total number of firms as follows:

$$
X_{i}=\sum_{j \neq i} \frac{\pi_{i j}}{F_{i j}^{\max }} q_{i j} n_{i}=n_{i} \sum \frac{q_{i j}^{3}}{F_{i j}^{\max }}
$$

Equation (4) implies three hypotheses about export of computer and information services. (i) Countries with a Ricardian comparative advantage in the production of computer and information services will export relatively more because the smaller $\mathrm{Cli}$ is, the greater $\mathrm{Xj}$ will be. (ii) Countries where the Internet is more developed export more because C1i is smaller; (ii) When two countries have a shorter "language distance" from each other, there will be more trade in computer and information services between them.Next, I explore how export changes with dij, the "language 
distance". There are two possible channels for language to affect exports of computer and information services. One channel is through marginal cost, the other channel for language to affect export is through fixed cost. Ease of communication obviously helps service suppliers to establish themselves in a foreign market with lower entry cost. Without specifying how dij works on Fijmax, we can write Fijmax (dij) as a decreasing function of dij.

The more a language is used in the world, the more beneficial for business to rely on it as a means of communication. This hypothesis has been tested many times in gravity models and seems to hold for trade in goods. However, trade in services, especially trade in computer and information services, is somewhat different in nature compared to trade in goods. First, language is a more important barrier when people trade services rather than goods. Second, as English is widely used as the language of computer and information technology, it may play a special role in trade of related services. Therefore, it is reasonable to believe that language distance, dij, and/or w, varies with the type of products and services being traded. In the case of export of computer and information services, I would like to make the following assumption: when $\mathrm{j}$ is an English speaking country, $\mathrm{dij} \in \mathrm{d} 0$ for English-speaking $\mathrm{i}$, dij $\in \mathrm{d} 1$ for non-English-speaking $\mathrm{i}$; when $\mathrm{j}$ is a non-English speaking country, dij $\in \mathrm{d} 2$ for Englishspeaking $\mathrm{i}, \mathrm{dij} \in \mathrm{d} 3$ for non-English-speaking $\mathrm{i}$ when $\mathrm{i}$ and $\mathrm{j}$ speak a common language, $\mathrm{dij} \in \mathrm{d} 4$ for non-English-speaking $\mathrm{i}$ when $\mathrm{i}$ and $\mathrm{j}$ speak different languages. $\mathrm{d} 0, \mathrm{~d} 1, \mathrm{~d} 2, \mathrm{~d} 3$ and $\mathrm{d} 4$ are intervals. Obviously elements in $\mathrm{d} 0$ represent the minimum distance while those in $\mathrm{d} 4$ represent the maximum distance due to the dominancy of English in the computer and information service industry. For the empirical work, it is useful to rewrite $\mathrm{Xi}$ in the following way,

$$
X_{i}=X_{i}\left(c_{1 i}, c_{2 i}, d_{i j}, \ldots\right)
$$

Equation (5) implies that a country's total volume of computer information services export is a function of productivity, the Internet development, language distances with other countries as well as a number of other parameters. The estimation equation is therefore

$$
\ln \left(\text { ITexport }_{i t}\right)=\beta_{1} \ln \left(\text { PCGDP }_{i t-1}\right)+\beta_{2} \ln \left(\text { INTERNET }_{i t-1}\right)+\beta_{3} L A N_{i}+\alpha_{i}+\varepsilon_{i t}
$$

In Equation (6), PCGDP serves as proxy for overall comparative advantage in services. A country with a higher per capita GDP (PCGDP) is likely to have a labor force skilled in services and has a demand for such services. Thus, the higher the PCGDP, the smaller c1i will be, the more the country is able to export ICT-enabled services. Likewise, I use Internet bandwidth as proxy for Internet development (INTERNET). LAN, the language variable, merits more detailed discussion in the next section.

\section{Description of the Data}

In order to investigate the relationship between language and export of computer and information services, I use unbalanced panel data of 76 countries over the period 2005-2008. To compare how export of computer and information services and export of ICT-enabled services are determined, I also test a panel date of 118 countries over the same period for the latter.Exports of computer and information services (ITexport) and ICT-enabled services in general (ITESexport) are obtained from UNCTAD website. GDP per capita and Internet Bandwidth data come from World Development Indicator (WDI) of the World Bank. As current trade volume normally reflects contracts signed earlier, one year lag regressors are used for PCGDP and INTERNET.

There are three candidate language variables, all based on the "open-circuit communication" (OCC) concept and data given in Melitze (2004). When a language is either official or widely spoken (i.e. possessed by at least 20 percent of the population) in more than one country, it is identified as an "open-circuit" language. For each country, at most two "open-circuit" languages are recognized. Some countries, such as China and Canada, possess 1 or 2 "open-circuit" languages, while Norway, do not share any "open-circuit" language with the rest of the world.

I give each "open-circuit" language a weight (OCCGDP), which is the aggregate Year 2005 GDP of all the countries sharing it. Each country's OCC value is the OCCGDP value of its "open-circuit" 
language minus its own Year 2005 GDP. In case the country possesses two "open-circuit" languages, we get two values for it, i.e. OCC1 and OCC2, and its OCC equals the sum of OCC1 and OCC2. Obviously, for countries without any "open-circuit" language, the OCCGDP value is 0 . Thus the first language measure, OCC, is constructed. It actually indicates the size of the potential market which shares the same language with the exporting country.The second and third measures are more straightforward to construct and interpret than OCC. If English is the OCC language of a country, then its EN variable is equal to 1, otherwise 0.

\section{Conclusion}

This paper identifies three most important determinants of export of computer and information services, i.e., productivity, the Internet development and language. It reveals that the world's dominant language, English, is effective in promoting export of such services, while other open-circuit languages, including European languages as a whole, does not play a role as such. The policy implications for non-English speaking countries like China is straightforward: in order to compete in the international computer and information services market, focusing on improvement in English is far more effective than promoting multi-lingualism.Due to lack of bilateral data, I only examine the role language plays in a country's total export of computer and information services. With UNCTAD and other international organization's efforts, more disaggregated data, either industry level or bilateral, might be available in the future. It is worthwhile to explore more thoroughly how language is related to trade with improved data. Another interesting extension of the present work is to further investigate why English is so important in export of computer and information services. Specifically, we need to show, both theoretically and empirically, whether this advantage comes from economy of scale, network externality, or both.

\section{References}

[1]. Eichengreen, B., Irwin, D., 1998. The role of history in bilateral trade flows. In: Frankel, J. (Ed.), the Regionalization of the World Economy. University of Chicago Press, Chicago, 33-62.

[2]. Freund, C., Weinhold, D., 2002. The Internet and international trade in services. American Economic Review, 236- 240.

[3]. .Freund, C., Weinhold, D., 2004. The effect of the Internet on international trade. Journal of International Economics, 62, 171- 189.

[4]. .Helliwell, J., 1999. Language and Trade. In: Breton, A. (Ed.), Exploring the Economics of Language. Canadian Heritage.

[5]. .Hung, Juann and Viana, Sandra. 1995. Modeling U.S. Services Trade Flows: A Cointegration-ECM Approach. Federal Reserve Bank of New York Research Paper No. 9518.

[6]. .Melitz, J., 2008. Language and Foreign Trade. Discussion Papers in Economics 03-10. University of Strathclyde.

[7]. .Song, L., Xue, Q., 2008. Location Choice of ICT-Enabled Services Offshoring: Evidence from 41 Host Countries. Asia-Pacific Economic Review, 08-01 


\section{Appendix}

Table 1 List of Countries in the First Estimation

\begin{tabular}{|c|c|c|c|}
\hline Albania & El Salvador & Lebanon & Saint Lucia \\
Argentina & Ethiopia & Madagascar & Senegal \\
Australia & Finland & Malaysia & Singapore \\
Austria & France & Mali & Spain \\
Bangladesh & Gabon & Malta & Sri Lanka \\
Belgium & Germany & Mauritius & Sudan \\
Bolivia & Greece & Mongolia & Sweden \\
Brazil & Guatemala & Mozambique & Syrian Arab Republic \\
Bulgaria & Guinea & Netherlands & Togo \\
Burkina Faso & Guyana & New Zealand & Tunisia \\
Canada & & Niger & Uganda \\
Chile & Hong Kong & Norway & United Kingdom \\
China & Hungary & Pakistan & United Republic of Tanzania \\
Colombia & Iceland & Paraguay & United States \\
Costa Rica & India & Philippines & Uruguay \\
Côte d'Ivoire & Ireland & Poland & Venezuela \\
Cyprus & Israel & Portugal & \\
Czech Republic & Italy & Republic of Korea & \\
Dominican Republic & Jamaica & Romania & \\
Egypt & Japan & Russian Federation & \\
& Kenya & & \\
\hline
\end{tabular}

Table 2 Estimation Results

Log of exports of ICT-enabled services (LN ITESexport)

\begin{tabular}{|c|c|c|}
\hline Independent Variables & LN ITexport & LN ITESexport \\
\hline LN(PCGDP) & $1.270^{* *}(0.139)$ & $0.735^{* *}(0.086)$ \\
\hline LN(INTERNET) & $0.179^{* *}(0.034)$ & $0.243^{* *}(0.029)$ \\
\hline EN & $1.149^{*}(0.502)$ & $-0.328(0.262)$ \\
\hline No. of observations & 262 & 397 \\
R2 & 0.64 & 0.68 \\
\hline
\end{tabular}

Note: Standard errors are in parentheses.* stands for significance at $2 \%$. ** stands for significance at $1 \%$. 